DOI: 10.15393/j9.art.2012.335

\author{
Владимир Николаевич Захаров \\ доктор филолологических наук, профессор, \\ заведуюший кафедры русской литературы и журналистики, \\ Петрозаводский государственный университет \\ (Петрозаводск, Российская Федерациия) \\ vnz01@yandex.ru
}

\title{
ПОЧВЕННИЧЕСТВО В РУССКОЙ ЛИТЕРАТУРЕ: МЕТАФОРА КАК ИДЕОЯОГЕМА*
}

Аннотация: В изучении такого своеобразного явления в русской идеологии и литературе, как почвенничество (pochvennichestvo), сложилось много мифов, ошибочных общих мест и заблуждений. Часто адептами этого направления называют тех, кто ими не был, приписывают почвенникам слова, понятия, идеи, о которых они не писали. Формирование идейной и литературной программы почвенничества связано с журнальной деятельностью братьев Достоевских - Федора и Михаила, издававших журналы «Время» (1861-1863) и «Эпоха» (1864-1865). Их установки и энергичные действия, обсуждения статей разных авторов на редакционных собраниях, полемика с другими изданиями способствовали созданию общего направления, в котором каждый влиял на всех. Решающая роль в развитии этого направления принадлежит Федору Достоевскому, который последовательно обосновывал новые идеи в русской литературе. В статье дан анализ метафоры «почва» в идеологии нового литературного направления и политического движения, созданного Достоевским в 1860-1870-е гг. Для Достоевского «почва» - все, что родит и роднит: народ, родина, родная речь, родная земля. Их объединяет тайна, которая заключается в том, что Россия - хранительница Православия, что «идеал народа Христос». Необходимо сблизиться с почвой - соединиться с народом, стремиться к единению всех сословий. Быть почвенником - любить Россию, народ, сознавать себя и быть русским, следовать вере отцов, чтить Отечество. В XX в. почвенничество стало разрешением старого спора западников и славянофилов. Почвенниками назвали тех писателей, кто сохранил верность крестьянству и традиционным ценностям народной жизни, традициям русской словесности. В этот круг пристрастно включают разных писателей и критиков, но там определенно есть Д. С. Лихачев и А. И. Солженицын, В. Г. Распутин и В. П. Астафьев, В. И. Белов и В. М. Шукшин.

Ключевые слова: gочвенничество, славянофильство, западничество, метафора, почва, идеологема, Достоевский, Страхов, Аполлон Григорьев

егодня история почвенничества во многом мистифицирована. Есть немало ошибочных общих мест и заблуждений. Почвенниками называют тех, кто почвенниками не был, а лишь встроился в фарватер журналов братьев Достоевских «Время» и «Эпоха» или спорил с ними, признают вклад в почвенничество тех, кто не разрабатывал и не развивал их идеологию, приписывают почвенникам слова, понятия, идеи, которые они не произносили, о которых не писали.

Почвенничество - поздний термин. Достоевский и его единомышленники не употребляли это слово, называя себя почвенниками, а иногда и славянофилами, впрочем, отмечая разность взглядов по ряду ключевых вопросов. 
Достоевский спорил со славянофилами, но признался в июльско-августовском выпуске «Дневника Писателя» за 1877 г.:

Я во многом убеждений чисто славянофильских, хотя может быть и не вполне славянофил. Славянофилы до сих пор понимаются различно. Для иных, даже и теперь, славянофильство, как в старину например для Белинского, означает лишь квас и редьку. Белинский, действительно дальше не заходил в понимании славянофильства. Для других (и заметим, для весьма многих, чуть не для большинства даже самих славянофилов), славянофильство означает стремление к освобождению и объединению всех славян под верховным началом России - началом, которое может быть даже и не строго политическим. И наконец, для третьих, славянофильство, кроме этого объединения славян под началом России, означает и заключает в себе духовный союз всех верующих в то, что великая наша Россия, во главе объединенных славян, скажет всему миру, всему европейскому человечеству и цивилизации его свое новое здоровое и еще неслыханное миром слово. Слово это будет сказано во благо и воистину уже в соединение всего человечества новым, братским, всемирным союзом, начала которого лежат в гении славян, а преимущественно в духе великого народа русского, столь долго страдавшего, столь много веков обреченного на молчание, но всегда заключавшего в себе великие силы для будущего разъяснения и разрешения многих горьких и самых роковых недоразумений западноевропейской цивилизации. Вот к этому-то отделу убежденных и верующих принадлежу и я ${ }^{1}$.

Литературным манифестом почвенничества по праву считается «Объявление об издании в 1861 году журнала 'Время'» (цензурное разрешение -6 сентября 1860 г.).

Приступая вместе с братом Михаилом к изданию, Достоевский ставил задачу создать новое направление в русской журналистике. Он справедливо полагал, что для успеха журнала нужны новые идеи и новое слово в истории идей.

Таким ключевым словом, которое выразило идейные устремления «Времени», стала идеологема почва. В «Объявлении» Достоевский впервые употребил это понятие, давшее имя новому идейному направлению:

Мы знаем теперь, что мы и не можем быть европейцами, что мы не в состоянии втиснуть себя в одну из западных форм жизни, выжитых и выработанных Европою из собственных своих национальных начал, нам чуждых и противуположных, - точно так как мы не могли бы носить чужое платье, сшитое не по нашей мерке. Мы убедились, наконец, что мы тоже отдельная национальность в высшей степени самобытная и что наша задача - создать себе новую форму, нашу собственную, родную, взятую из почвы нашей, взятую из народного духа и из народных начал $(\mathrm{V}, 8)$.

Здесь же Достоевский сформулировал программную идею нового журнала:

Мы предугадываем и предугадываем с благоговением, что характер нашей будущей деятельности должен быть в высшей степени общечеловеческий, что русская идея, может быть, будет синтезом всех тех идей, которые с таким упорством, с таким мужеством развивает Европа, в отдельных своих 
национальностях; что, может быть, все враждебное в этих идеях найдет свое примирение и дальнейшее развитие в русской народности $(\mathrm{V}, 8)$.

Провозглашая новое направление, Достоевский не желал выбирать чью-либо сторону. Писатель высоко чтил «чистое, идеальное славянофильство», но и критиковал их «московскую затею», «московскую формулу» учения. По его мнению, славянофильство придумало «поэтическую грезу воссоздать Россию по идеальному взгляду на древний быт, взгляду, составившему вместо настоящего понятия о России какую-то балетную декорацию, красивую, но несправедливую и отвлеченную» $(\mathrm{V}, 14)$, создало романтический миф о России, который состоит «из некоторых удачных изучений старинного нашего быта, из страстной, но несколько книжной и отвлеченной любви к отечеству, из святой веры в народ и в его правду, а вместе с тем (зачем утаивать? отчего не высказать?) - из панорамы Москвы с Воробьевых гор, из мечтательного представления московских бар половины семнадцатого столетия, из осады Казани и Лавры и из прочих панорам, представленных во французском вкусе Карамзиным, из впечатления его же Марфы-посадницы, прочитанной когда-то в детстве, и наконец, из мечтательной картины полного будущего торжества над немцами, несколько даже физического, - над немцами непрощенными и даже, уже после торжества над ними, попрекаемыми (IV, 469).

Он упрекал:

Славянофилы имеют редкую способность не узнавать своих и ничего не понимать в современной действительности (IV, 467).

Ему претили «аристократизм» славянофилов, их пренебрежительное отношение к современной русской литературе.

Позже Достоевский почти всегда нелицеприятно отзывался о западниках, видя в них «лакейство мысли», упрекая их за отрицание самобытности и даже ненависть к России, к православию, к народу и монархии, но в ноябре 1861 г. он писал в пятой из «Ряда статей о русской литературе» по поводу славянофильской газеты «День», что славянофилы чему-то научили западников, а западники - славянофилов, утверждал, что западничество «реальнее» славянофильства, заблуждался в том, что западники восприняли почвеннические идеи:

...западничество все-таки было реальнее славянофильства, и несмотря на все свои ошибки, оно все-таки дальше ушло, все-таки движение осталось на его стороне, тогда как славянофильство постоянно не двигалось с места и даже вменяло это себе в большую честь. Западничество смело задало себе последний вопрос, с болью разрешило его и через самосознание, воротилось-таки на народную почву и признало соединение с народным началом и спасение в почве (IV, 469). 
«Почва» - распространенная языковая метафора, которая представлена в критическом тезаурусе 1840-1860-х гг. В прямом значении - это земля, в переносном - основа, основание, опора.

O «почве» в метафорическом смысле писали немногие. Журналисты не сразу придали значение этому слову, но в полемике «Времени» с «Русским Вестником», «Отечественными Записками» и «Современником» «почва» стала ключевым понятием, давшим имя новому литературному направлению.

Кроме Достоевского, нечасто употребляли это слово и те, кого называют почвенниками.

Слово почва почти отсутствует в критическом тезаурусе Н. Н. Страхова. Его редко употреблял А. А. Григорьев ${ }^{2}$. Он никогда не превращал метафору в идеологему; иногда в его статьях возникает поясняющий синонимический ряд к слову почва: народ, народная жизнь, народная правда, национальная культура, «действительность»; порой это слово поясняет другое понятие: «натура, то есть почва и среда».

На смысловую неопределенность метафоры обратил внимание один из первых критиков почвенничества М. А. Антонович. В фельетоне «'О почве' (не в агрономическом смысле, а в духе 'Времени')» (Современник. 1861. № 12) он упрекал оппонентов, что «спорящие имеют неопределенное, не собственное, а тоже аллегорическое понятие о предмете спора, т. е. толкуют о том, чего никто из них не потрудился уяснить для себя» $[1,354]$. Пародируя общие места почвеннической публицистики, критик «Современника» поучал публицистов «Времени»: чтобы сблизиться с народом, нужны грамотность и «капиталец», чтобы учиться:

...заботящиеся о грамотности народа и о сближении с почвой должны вместе с тем позаботиться об улучшении его внешнего быта и увеличении его материального благосостояния $[1,374]$.

Во «Времени» на критику М. А. Антоновича ответил Страхов ответил, как всегда, ничего не объяснив: покритиковал оппонента за упреки, обозначил метафору, так и не растолковав ее смысл $[5,58-$ 75]. Это единственная статья Страхова, в которой он по необходимости много говорит о «почве». Свое мнение о «почве» пыталась заявить и редакция журнала «Светоч» ${ }^{3}$, но ее участие в полемике не внесло ясности в предмет спора.

Впрочем, возникновение почвенничества связано не с тем, кто использовал это слово в метафорическом смысле, а с теми, кто сделал метафору идеологемой, а почвенничество идеологией нового литературного направления.

Кто они, почвенники?

Сегодня прежде Достоевского почвенниками часто называют Аполлона Григорьева и Николая Страхова. 
А. Григорьев не был идеологом почвенничества, он был славянофилом. Он стал автором «Времени» со второго номера за 1861 г. Его пребывание в кругу Достоевских было недолгим - менее полугода. В 1862 г. он вернулся к сотрудничеству, но подчеркивал самостоятельность и независимость в своих суждениях. Его литературно-критическая и эстетическая позиция не всегда совпадала с редакционными мнениями журнала. Он - почвенник в той мере, в которой почвенничество следует славянофильству.

В 1861-1865 гг. Страхов был одним из ведущих сотрудников журналов братьев Достоевских «Время» и «Эпоха». Достоевский возлагал на Страхова болышие надежды. Ему казалось, что Страхов может быть критиком, публицистом, полемистом, фельетонистом. Он поручал Страхову многое, но тот тяготился своей зависимостью от Достоевского, от его уроков литературного мастерства. По складу ума Страхов был критиком и аналитиком; ему, как отмечали современники, не давался синтез. Его жанр - философская критика. Названия его книг и статей радикальнее их содержания. Он боролся с Западом и нигилизмом, материализмом и дарвинизмом, но у него не было своих оригинальных идей. Когда Страхов был в орбите Достоевского, он становился почвенником, с А. Григорьевым - славянофилом, в орбите Л. Толстого - рационалистическим критиком церкви и ее учения. Можно спорить, веровал ли Страхов в Бога или был атеистом, был церковен или антицерковен, - в разные годы было и то, и другое.

Достоевский подозревал бывшего семинариста в неверии. Страхов подтвердил и эти подозрения Достоевского: незадолго до смерти он сознательно отказался от исповеди и принятия Святых тайн ${ }^{4}$.

Л. М. Розенблюм остроумно и метко назвала Страхова «почвенником без почвы» $[6,19]$. Этому мнению есть основания. Страхов не только не формулировал и не распространял почвеннические идеи, предпочитал славянофильство, но в течение жизни не раз размежевывался с Достоевским. В августе 1862 г. во Флоренции во время одной из прогулок, когда произошло конфликтное выяснение отношений Достоевского и Страхова, о чем тот писал в своих «наблюдениях»:

Вы тогда объявили мне с величайшим жаром, что есть в направлении моих мыслей недостаток который вы ненавидите, презираете и будете преследовать всю свою жизнь...

В 1875-1876 гг. Страхов завел литературную полемику с Достоевским на страницах еженедельника «Гражданин»: в мае 1875 г. - в двух корреспонденциях из Рима, в течение 1876 г. - в «Трех письмах о спиритизме». Мало кто из читателей догадался, что корреспонденции Страхова адресованы не читателям, а Достоевскому. 
После его путешествия по Европе летом 1862 г., к которому присоединился Страхов, Достоевский написал «Зимние заметки о летних впечатлениях». В полемике с Достоевским Страхов шлет из Рима свои «весенние заметки».

В отличие от других «русских путешественников», Карамзина и Достоевского, Страхов - турист, который избегает идейных споров, его волнуют не идеи, а присутствие в мировой истории, бытовой комфорт.

Описывая итальянские впечатления, он, несмотря на то, что сравнение Мойки, Петербурга, Москвы не в пользу Венеции и Рима, признается в «чувстве благоговения к Западу»:

Сравнительно хоть бы с нашим пышным Петербургом, все здесь жалко и мизерно. Но от подобных сопоставлений меня избавляет то чувство благоговения $\kappa$ Западу, которое иногда шевелится во мне с необыкновенною силою $[8,479]^{6}$.

Слова «благоговение к Западу» Страхов выделил курсивом. Он раскрывает это чувство, рассуждает о всемирной истории, хвалит римскую историю, по сравнению с которой Россия не имеет истории:

Когда здесь, в Риме, вспомнить о России, кажется, как будто она вовсе не имеет истории; все ее прошедшее представляется однообразною полосою роста. Великие бедствия, которые она вынесла, создание крепкого государства; все это не история, все это только явления самосохранения; а истории как будто еще не было. Но что же тут печального? Вот передо мною римляне, у которых не одна, а даже три истории; кто же из нас пожелал бы с ними поменяться? Иные горько жалуются, что цивилизация у нас не принимается. В самом деле, вот скоро два столетия, как она привита к нам, а до сих пор ее дело идет плохо, и недавно новая решительная попытка поправить это дело - заведены классические гимназии. Эти неудачи имеют, по-моему, смысл нисколько не печальный $[8,479]$.

Сопоставляя русскую и римскую историю, Страхов разъясняет свою критику России:

Мы усвояем из цивилизации все внешнее, все то, что не касается самого духа, самой глубины развития, а только дает ему простор или охраняет. Говорят, наша артиллерия очень недурна; железные дороги тоже порядочные и их уже много; юридические формы нашего быта в настоящую минуту довольно широки и свободны, несмотря на некоторую путаницу; Петербург и Москва у нас и красивее, и во многом щегловатее, барственнее Берлина и Вены. Но дух, - да, мы не усвоили духа $[8,479]$.

Какой «дух»? - вопрос риторический: «дух Запада».

Презрительно, свысока сказано о народе:

Мы не знаем, для чего они так берегут себя; для нас непонятно то таинственное будущее, из-за которого они так мало дорожат своими головами; но ведь это уж наша печаль, а не их $[8,479]$.

Разве это почвенник говорит? 
В цикле статей «Три письма о спиритизме», опубликованных в трех номерах «Гражданина» от 15, 22 и 29 ноября 1876 г. (№ 41-42, 43, 44), Страхов продолжил спор с Достоевским на странную тему, сколько будет дважды два (подробнее об этом см.: [3]).

И все же очевидно, что среди почвенников был тот, кто придумал это направление, задумал «новое слово», формулировал почвеннические идеи «Времени» и «Эпохи», объяснял смысл слова.

В сентябрьском 1860 г. «Объявлении об издании в 1861 году журнала 'Время'» Достоевский высказал альтернативу западничеству и славянофильству:

И вот перед этим - то вступлением в новую жизнь, примирение последователей реформы Петра с народным началом стало необходимостию. Мы говорим здесь не о славянофилах и не о западниках. К их домашним раздорам наше время совершенно равнодушно. Мы говорим о примирении цивилизации с народным началом. Мы чувствуем, что обе стороны должны, наконец, понять друг друга, должны разъяснить все недоумения, которых накопилось между ними такое невероятное множество, и потом согласно и стройно общими силами двинуться в новый широкий и славный путь. Соединение во что бы ни стало, несмотря ни на какие пожертвования и возможно скорейшее - вот наша передовая мысль, вот девиз наш (V, 9).

В полемике с «Современником» Достоевский приготовил такой финал статьи:

Мы вовсе не такие почвенники, чтоб отвергать общечеловеческий идеал и призывая к почве - тупить людей суживать их горизонт и стеснять горизонт. Мы потому, главное, не таковы что Христиане, вполне Христиане. А первый догмат Христианства - общ<н>ость закона для всех, общность идеала, все братья, «Шедше научите вся языцы» и проч. Поймите-же нас. Мы почвенники, во $1^{\mathrm{x}}$ потому, что верим, что ничего на свете не происходит отвлеченно (вне настоящей, исторической жизни) и скачками ${ }^{7}$.

В записных тетрадях к «Бесам» есть набросок:

Схема веры: - православие заключает в себе образ Иисуса Христа.

- Христос - начало всякого нравственного основания.

- Развиваться и идти далее $\kappa$ чему-бы это начало ни привело (к понятию о счастии во-первых; счастие в Законе чтоб другие были счастливы. Это не стадное устройство Западных социалистов на правах, а все права само собою исходят из определения счастья по Иисусу. Не в накоплении вещей у себя по ревнивому праву личности, а в отдании всех прав добровольно мое счастье. Это не рабство, ибо во $\left.1^{\underline{x}}\right)$ отдает добровольно, след<овательно> высшее проявление личности, а во-вторых и те взаимно мне все отдают.

- Нечего глядеть если это не осуществимо; хотя бы только тысячному дана была белая одежда (Апокалипсис) и того довольно.

- Из сознания: в чем счастье? последует и устройство общества.

Но чтоб сохранить Иисуса, т. е. православие, надо первее всего сохранить себя и быть самим собою. Только тогда будет плод, когда сберется и разовьется дерево; и потому России надо: проникнувшись идеей какого 
сокровища она одна остается носительницей, - свергнуть иго немецкое и Западническое и стать самой собою с ясно сознанной целью ${ }^{8}$.

В июньском выпуске «Дневника Писателя» за 1876 г., вспоминая Жорж Занд, Достоевский писал:

У нас - русских, две родины: наша Русь и Европа, даже и в том случае, если мы называемся славянофилами, - (пусть они на меня за это не сердятся). Против этого спорить не нужно. Величайшее из величайших назначений, уже сознанных Русскими в своем будущем, есть назначение общечеловеческое, есть общеслужение человечеству, - не России только, не общеславянству только, но всечеловечеству. Подумайте и вы согласитесь, что Славянофилы признавали то же самое, - вот почему и звали нас быть строже, тверже и ответственнее русскими, - именно понимая, что всечеловечность есть главнейшая личная черта и назначение русского (XI, 423).

В том же выпуске «Дневника Писателя» Достоевский продолжил защиту славянофильской точки зрения:

...Россия вовсе была не Европа, а только ходила в европейском мундире, но под мундиром было совсем другое существо. Разглядеть, что это не Европа, а другое существо и приглашали славянофилы, прямо указывая, что западники уравнивают нечто непохожее и несоизмеримое, и что заключение, которое пригодно для Европы, неприложимо вовсе к России, отчасти и потому уже, что все то, чего они желают в Европе, - все это давно уже есть в России, по крайней мере в зародыше и в возможности, и даже составляет сущность ее, только не в революционном виде, а в том в каком и должны эти идеи всемирного человеческого обновления явиться: в виде Божеской правды, в виде Христовой истины, которая когда-нибудь да осуществится же на земле, и которая всецело сохраняется в православии (XI, 432).

Никто, кроме Достоевского, не прорицал будущность России. Почвенничество и есть его новое слово в истории идей.

Среди сотрудников журналов «Время» и «Эпоха» единомышленниками и соратниками были лишь братья Достоевские, их согласные установки и энергичные действия, обсуждения будущих статей разных авторов на редакционных собраниях, полемика с другими изданиями способствовали созданию общего направления, в котором каждый влиял на всех, каждый был причастен к общему делу, расширяя круг почвенников.

Для Достоевского «почва» - все, что родит и роднит: народ, родина, родная речь, родная земля. Их объединяет тайна России. Ее не понимают не только иностранцы, но и сами русские. Незнание и непонимание России дошло до такой степени, что России нужно учиться. Сокровенная тайна России заключается в том, что она - хранительница Православия (XI, 437, 440), что «идеал народа - Христос» (XII, 334), в мире Достоевского, как верно отметил священник Александр Ранне, Христос - «мера всех вещей». 
Сблизиться с почвой - соединиться с народом, стремиться к единению всех сословий в любви к Родине, к России, к идеалам и ценностям.

Быть почвенником - любить Россию, народ, сознавать себя и быть русским, следовать вере отцов, чтить Отечество.

Достоевский обнаружил эти идеи в политических ямбах 18541856 гг., которые мало ценят читатели и исследователи. В них засвидетельствовано не только перерождение прежних убеждений, но и выражены новые воззрения, положившие начало новому литературному направлению.

В XX в. почвенничество стало разрешением векового спора западников и славянофилов. Почвенниками назвали тех писателей, кто сохранил верность крестьянству и традиционным ценностям народной жизни, традициям русской словесности. В этот круг пристрастно включают разных писателей и критиков, но там определенно есть Д. С. Лихачев и А. И. Солженицын, В. Г. Распутин и В. П. Астафьев, В. И. Белов и В. М. Шукшин.

Сегодня мы живем в мире, в котором нет России Достоевского, нет народа, который образовывали крестьянство, духовенство, купечество, нет почвы, на которой взросла русская словесность и культура, - есть постсоветская Россия, в которой печатные и электронные средства информации убеждают нас, что стыдно быть гражданином, патриотом, называть себя русским.

Императив Достоевского - «не стыдиться».

Сегодня часто обсуждают, есть ли будущее у русской литературы.

Уже стало общим местом мнение, что будущее русской литературы - ее прошлое. Эти слова имеют двойной смысл: с одной стороны, прошлое может быть залогом будущности русской словесности, с другой - у русской литературы нет будущего, всё в прошлом. Приговор безжалостен, но справедлив, и от нас зависит, есть ли будущее у русской словесности, будут ли читатели русской классики есть ли будущее у России.

\section{Примечания}

* $\quad$ Работа выполнена при финансовой поддержке Программы стратегического развития ПетрГУ на 2012-2016 гг. в рамках реализации комплекса мероприятий по развитию научно исследовательской деятельности.

1 Достоевский Ф. М. Полн. собр. соч.: В 18 т. М.: Воскресенье, 2004. Т. 12. С. 177. Далее ссылки на это издание, сохраняющее авторскую пунктуацию и отчасти авторскую орфографию, даны в тексте с указанием тома и страницы.

2 Исключение - его статья «Стихотворения Некрасова» (Время. 1862. № 7), в которой он в полной мере отработал программные установки редактора журнала М. М. Достоевского, заказавшего ему эту статью.

3 О почве, не в агрономическом смысле и не в духе «Времени», но также и не в духе «Современника» // Светоч. 1862. № 2. С. 1-26. 
4 См. свидетельство одного из конфидентов Страхова: «Действительно, как я убедился во время болезни Страхова (у него был рак в полости ушей и на языке, ему делали операцию), он был человек неверующий, хотя думал, что религия нужна для народа. Мягкий и кроткий, он сильно раздражился, когда я упомянул о священнике перед операцией, и скончался без церковного напутствия» $[4,157]$.

5 Н. Н. Страхов о Достоевском / Ст., публ. и коммент. Л. Р. Ланского // Литературное наследство. Ф. М. Достоевский. Новые материалы и исследования. Т. 86. М.: Наука, 1973. С. 560.

6 Первая корреспонденция была опубликована в 19-м номере 11 мая 1875 г. При переиздании «корреспонденций» Страхов добавил к заглавию подзаголовок, раскрывающий адресата посланий: «К А. Н. Майкову» (см.: $[7,87])$. РГАЛИ. 212.1.04. С. 147.

8 НИОР РГБ. 93. І. 1. 5. С. 38.

\section{Список литературы}

1. Антонович М. А. Избранные статьи. Философия. Критика. Полемика. Л.: Художественная литература, 1938. 583 с.

2. Григорьев А. А. Стихотворения Некрасова // Время. 1862. № 7. [Электронный peсурс]. Режим доступа: http://philolog.petrsu.ru/fmdost/index.html (дата обращения: 25.10.2011).

3. Захаров В. Н. Сколько будет дважды два, или неочевидность очевидного в поэтике Достоевского // Вопросы философии. 2011. № 4. С. 109-115.

4. Матвеев П. А. Л. Н. Толстой и Н. Н. Страхов в Оптиной пустыни // Исторический Вестник. 1907. Т. 108. Март, апрель, май. С. 151-158.

5. Н. Косии $а<$ Страхов Н. Н.> Пример апатии (Письмо в редакцию «Времени» по поводу статьи г. Антоновича «О почве». «Современник», 1861, декабрь) // Время. 1862. № 1. С. $58-75$.

6. Розенблюм Л. М. Творческие дневники Достоевского // Литературное наследство. Ф. М. Достоевский. Новые материалы и исследования. Т. 83. М.: Наука, 1971. С. 9-92.

7. Страхов Н. Воспоминания и отрывки. СПб.: Типография бр. Пантелеевых, $1892.313 \mathrm{c}$.

8. Страхов Н. Из Рима (Корреспонденция «Гражданина») // Гражданин. 1875. № 20.18 мая. С. $478-479$.

Vladimir Nikolaevich Zakharov Doctor of Philology, Professor, Head of the Department of Russian Literature and Journalism, Petrozavodsk State University (Petrozavodsk, Russian Federation) vnz01@yandex.ru

\section{POCHVENNICHESTVO IN RUSSIAN LITERATURE: THE METAPHOR AS IDEOLOGEME}

Abstract: Original as it was, the phenomenon of pochvennichestvo (roughly translated as «native soil») in Russian thought and literature is often accompanied by a number of myths, misperceptions and erroneous commonplaces. It is not infrequent that those who never shared the ideas of pochvennichestvo are described as its adepts, and those who did, are often misquoted, with some notions, ideas and phrases misattributed 
to them. The ideological and literary agenda of pochvennichestvo was formed by the Vremya (1861-1863) and Epokha (1864-1865) magazines published by the brothers Dostoevsky - Fedor and Mikhail. Their outlook and vigorous action, discussions of submitted articles at board meetings, polemics with other periodicals all of these factors contributed to the general trend of pochvennichestvo with its typical mutual influence of all its members. Fedor Dostoevsky's role on its development was decisive, as he kept consistently substantiating ideas which were new for Russian literature. Our article analyses the pochva (soil) metaphor in the ideology of new school of literature and political movements which Dostoevsky helped set up in 1860s-1870s. According to him, pochva includes everything that gives birth and unites: people, homeland, native language and mother earth. They are all linked together by the mystery of Russia as the keeper of Orthodox faith and Christ as the «ideal of the people». One has to reunite with the pochva by becoming one with the people and strive to see all estates united. To be a pochvennik meant to love Russia and its people, to be a Russian and identify as one, to follow the faith of the fathers and honour the native land. In the 20th century, pochvennichestvo resolved the old argument between the Westernizers and Slavophiles. The word pochvennik was applied to the authors who stayed loyal to Russian traditional values, rural communities and traditions of Russian literature. Various authors and critics have been included in this circle, but it definitely includes D. S. Likhachev and A. I. Solzhenitsyn, V. G. Rasputin and V. P. Astafiev, V. I. Belov and V. M. Shukshin.

Keywords: pochvennichestvo, Slavophilism, Westernism, metaphor, the soil, ideologeme, Dostoevsky, Strakhov, Apollon Grigoryev

\section{References}

1. Antonovich M. A. Izbrannye stat'i. Filosofiya. Kritika. Polemika [Selected Articles. Philosophy. Criticism. Polemics]. Leningrad, Khudozhestvennaya literatura Publ., 1938. $583 \mathrm{p}$.

2. Grigor'ev A. A. Stikhotvoreniya Nekrasova [The Poems by Nikolai Nekrasov]. Vremya [Time], 1862, no. 7. Available at: http://philolog.petrsu.ru/fmdost/index.html (accessed 25.10.2011)

3. Zakharov V. N. Skol'ko budet dvazhdy dva, ili neochevidnost' ochevidnogo v poetike Dostoevskogo [How much is Two and Two, or the Unobviousness of the Obviousness in Fyodor Dostoyevsky's Poetics]. Voprosy filosofii [The Questions of Philosophy], 2011, no. 4, pp. 109-115.

4. Matveev P. A. L. N. Tolstoy i N. N. Strakhov v Optinoy pustyni [Leo Tolstoy and Nikolai Strakhov in the Optina Monastery]. Istoricheskiy Vestnik [The Historical Messenger], 1907, vol. 108, March, April, May, pp. 151-158.

5. N. Kositsa $<$ Strakhov N. N. $>$ Primer apatii (Pis'mo v redaktsiyu «Vremeni» po povodu stat' $i$ g. Antonovicha "O pochve». «Sovremennik», 1861, dekabr') [An Example of Apathy (Letter to the "Time" Magazine Editor relating to the Article "On the Soil" by M. Antonovich. "The Contemporary”, 1861, December)]. Vremya [Time], 1862, no. 1, pp. 58 -75.

6. Rozenblyum L. M. Tvorcheskie dnevniki Dostoevskogo [Art Diaries by Fyodor Dostoyevsky]. Literaturnoe nasledstvo. F. M. Dostoevskiy. Novye materialy i issledovaniya [Literary Heritage. Fyodor Dostoyevsky. New Materials and Studies]. Moscow, Nauka Publ., 1971, vol. 83, pp. 9-92.

7. Strakhov N. Vospominaniya i otryvki [Memories and Fragments]. Saint-Petersburg, The Panteleevs' Publ., 1892. 313 p.

8. Strakhov N. Iz Rima (Korrespondentsiya «Grazhdanina») [From Rome ("The Citizen” Magazine Correspondence)]. Grazhdanin [“The Citizen”], 1875, no. 20, May 18, pp. $478-479$. 